\title{
AN EVALUATION OF VELOCITY ESTIMATES WITH A CORRELATED NOISE: CASE STUDY OF IGS ITRF2014 EUROPEAN STATIONS
}

\author{
Anna KLOS * and Janusz BOGUSZ \\ Military University of Technology, Faculty of Civil Engineering and Geodesy, S. Kaliskiego 2, 00-908 Warsaw, Poland \\ *Corresponding author's e-mail: anna.klos@wat.edu.pl
}

\section{ARTICLE INFO}

Article history:

Received 2 January 2017

Accepted 9 March 2017

Available online 29 March 2017

Keywords:

ITRF2014

GPS

Noise analysis

Velocity

\begin{abstract}
The velocities of the Global Positioning System (GPS) stations are widely employed for numerous geodynamical studies. The aim of this paper is to investigate the reliability of station velocities and to draw reader's attention that for proper estimates of velocity, we need to consider the optimal character of noise. We focus on a set of 115 European GPS stations which contributed to the newest release of the International Terrestrial Reference Frame (ITRF), i.e. ITRF2014. Based on stacked Power Spectral Densities (PSDs), we show that amplitudes of seasonal signals are significant for nine harmonics of tropical year (365.25 days) and two harmonics of draconitic year (351.60 days). The amplitudes of tropical annual signal fall between 0.1-8.4 mm and are much higher for vertical component than for horizontal. Draconitic annual signal reaches the maximum amplitudes of 1.2 and $0.9 \mathrm{~mm}$ for North and East, respectively, whereas is slightly higher for the Up component with a maximum of $3.1 \mathrm{~mm}$. We performed a noise analysis with Maximum Likelihood Estimation (MLE) and found that stations in Central and Northern Europe are characterized by spectral index between flicker and randomwalk noise, while stations in Southern and Western Europe: between white and flicker noise. Both amplitudes and spectral indices of power-law noise show a spatial correlation for Up component. We compared the uncertainties of velocities derived in this study with a combination of power-law and white noises to the ones officially released in the ITRF2014 with a pure white noise. A ratio of the two estimates is larger than 10 for $13 \%$ and $30 \%$ of stations in horizontal and vertical direction, respectively with medians of 6 and 7. The large differences support the fact that at the velocity determination the proper noise characteristic should be taken into account to avoid any mislead interpretation.
\end{abstract}

\section{INTRODUCTION}

The secular velocities derived from Global Positioning System (GPS) position time series are being widely employed to validate the Glacial Isostatic Adjustment (GIA) models (e.g. Métivier et al., 2012; Kierulf et al., 2014), to estimate crustal deformations (e.g. Campbell and Nothnagel, 2010) or to correct the tide gauge records of vertical land motion (e.g. Teferle et al., 2006; Wöppelmann and Marcos, 2016). These applications of crustal velocities impose the reliability which should be correctly handled at their estimations based on GPS position time series. Accounting for reliable velocities, all processes that may affect the estimates have to be included. As was shown by Blewitt and Lavallée (2002), the estimates of velocity may be biased when annual signal is not accounted for. However, during their considerations only a pure white noise was assumed in the residuals. Bos et al. (2010) discussed this topic by adding a power-law noise into residuals and found that the stochastic properties of GPS data contribute more into velocity uncertainty than seasonal signals. Nowadays, it is widely acknowledged that residuals of GPS position time series are characterized by a combination of a powerlaw and white processes which is close to flicker noise (e.g. Zhang et al., 1997; Williams et al., 2004). Nevertheless, if the monument where the antenna is mounted on is not stable enough, then the character of residuals will move towards random-walk noise (Beavan, 2005; Klos et al., 2016a). This will cause the velocity error to increase and prolong the time to reach a value of $1 \mathrm{~mm} / \mathrm{yr}$ of few times (Beavan, 2005). Furthermore, if a white noise only model is wrongly assumed to describe the stochastic part of GPS data instead of choosing the combination of power-law and white noise processes, an underestimation of velocity uncertainty up to 10 times is expected (Klos et al., 2014).

The consecutive realizations of International Terrestrial Reference Systems (ITRS; McCarthy and Petit, 2004) are computed using data from Satellite Laser Ranging (SLR), Doppler Orbitography and Radio-positioning Integrated by Satellites (DORIS), Very Long Baseline Interferometry (VLBI) and GPS. The newest realization of ITRS, International 
Terrestrial Reference Frame ITRF2014 (Altamimi et al., 2016), has been released in January 2016. ITRF2014 is superior to past realizations of the ITRS, as includes more input data in quantity and quality and additionally exhibit new features as modelling the changes in the velocity in time with piece-wise linear functions and post-seismic deformations, being modelled by exponential and/or logarithmic functions. The employed model is very consistent with the recent station trajectory model described by Bevis and Brown (2014).

In this research, we estimate the velocities of European GPS stations that contributed to the latest realization of ITRS. We juxtapose the errors of estimated velocities using a combination of power-law and white processes with the officially released uncertainties of ITRF2014 velocities, upon whitenoise-only assumption. Beyond velocities, we also consider the character of stacked Power Spectral Densities (PSDs) of selected ITRF2014 European stations and the character of seasonal oscillations, providing the exact statistics. All above is discussed in a view of reliable estimates of velocities.

\section{DATA}

In the following research, we employed the GPS position time series of 115 European stations between 1995 and 2015 with the minimum length of 10 years (as plotted in Figure 2). They were processed in the frame of International GNSS Service (IGS, Beutler et al., 1999) "repro2" activity and contributed in the newest release of International Terrestrial Reference Frame ITRF2014 (Rebischung et al., 2016). Time series were accessed from http://acc.igs.org/reprocess $2 . h t m l$ Initially, the daily sampled data were examined with the Interquartile Range (IQR) approach to remove outliers. We used the offsets defined in the IGS database, but basing on the manual inspection of data applied also the stationspecific offsets which were not reported in the database. The number of 115 series was characterized by a median of $15 \%$ of missing values. We interpolated all gaps up to 30 days using a combination of data-specific deterministic model and white noise. Right after the interpolation was completed, the median percent of gaps changed from $15 \%$ into $1 \%$ of entire data.

\section{METHODOLOGY}

In this research, we assumed that the station trajectory model follows a sum of initial value $x_{0}$, velocity $v$, offsets defined by the Heaviside step function $H$, seasonal signals of periods equal to tropical $(T)$ and draconitic $(D)$ oscillations along with a stochastic part, which is a combination of power-law and white noises:

$$
\begin{aligned}
\mathbf{X}(t) & =x_{0}+v \cdot t+\sum_{i=1}^{n} J_{i} \cdot H\left(t-t_{j}\right)+ \\
& +\sum_{i=1}^{9}\left[S T_{i} \cdot \sin \left(\omega_{i} \cdot t\right)+C T_{i} \cdot \cos \left(\omega_{i} \cdot t\right)\right]+ \\
& +\sum_{i=1}^{9}\left[S D_{i} \cdot \sin \left(\omega_{i} \cdot t\right)+C D_{i} \cdot \cos \left(\omega_{i} \cdot t\right)\right]+\varepsilon
\end{aligned}
$$

where $S T$ and $C T$ are sine and cosine terms, respectively.

We assumed that one tropical year (365.25 days) as well as one draconitic year (351.60 days; AmiriSimkooei, 2013) go along with its nine harmonics to be consistent with Bogusz and Klos (2016) findings.

The stochastic part, being a combination of power-law and white noises implies the following form of the covariance matrix:

$$
\mathbf{C}_{\mathbf{x}}=a^{2} \cdot \mathbf{I}+b_{\kappa}^{2} \cdot \mathbf{J}_{\mathbf{\kappa}}
$$

where $a$ is the amplitude of white noise, $b_{\kappa}$ is the amplitude of power-law noise of spectral index $\kappa$.

The deterministic model we employed was supported by the analysis of Power Spectral Densities (PSD) which was stacked for a set of 115 European stations we employed in this research (Figure 1). The PSD was estimated with Lomb-Scargle periodogram (Lomb, 1976; Scargle, 1982), stacked and averaged with a moving window. Although, when averaged, North and East components do not show prominent oscillations, the individual stations reveal significant peaks of 1, 2, 3 and 4 cpy. The PSD of Up component looks quite different. Clear and significant peaks of 1 , 2, 3 and 4 cpy can be noticed for stacked PSDs. Also, a comb peak around 1 and 2 cpy may indicate significant draconitic oscillations of a year and half-a-year. A power-law behaviour of GPS data becomes apparent when looking at the stacked PSDs. Horizontal components show clear flicker noise (spectral index of -1) for low frequencies up to 100 cpy. Highest frequencies reveal obvious white noise (flat spectrum). For low frequencies, Up component is less flicker than North and East. However, similarly to North and East, a high frequency part of spectrum has a character of white noise.

We modelled our data by solving the Eq. (1) with reformulated Maximum Likelihood Estimation (MLE; Bos et al., 2008) in the Hector software (Bos et al., 2013a) assuming a combination of power-law and white noises in the stochastic part. Residuals are formed here as a difference between data and the analytical (deterministic) model we used. In this way, we deliver the uncertainties of ITRF2014 velocities with the most realistic noise model in the form of (Bos et al., 2008):

$$
\sigma_{v} \approx \pm \sqrt{\frac{\sigma_{P L}^{2}}{\Delta T^{2-\frac{\kappa}{2}}} \frac{\Gamma(3-\kappa) \Gamma(4-\kappa)(N-1)^{\kappa-3}}{\left(\Gamma\left(2-\frac{\kappa}{2}\right)\right)^{2}}}
$$

\section{RESULTS}

In the following section, we describe the results of methods we applied. We focus on the amplitudes and phases of seasonal changes, properties of stacked and individual PSDs, character of stochastic part and provide statistics of both horizontal and vertical velocities along with the uncertainties estimated for a combination of power-law and white noises. 


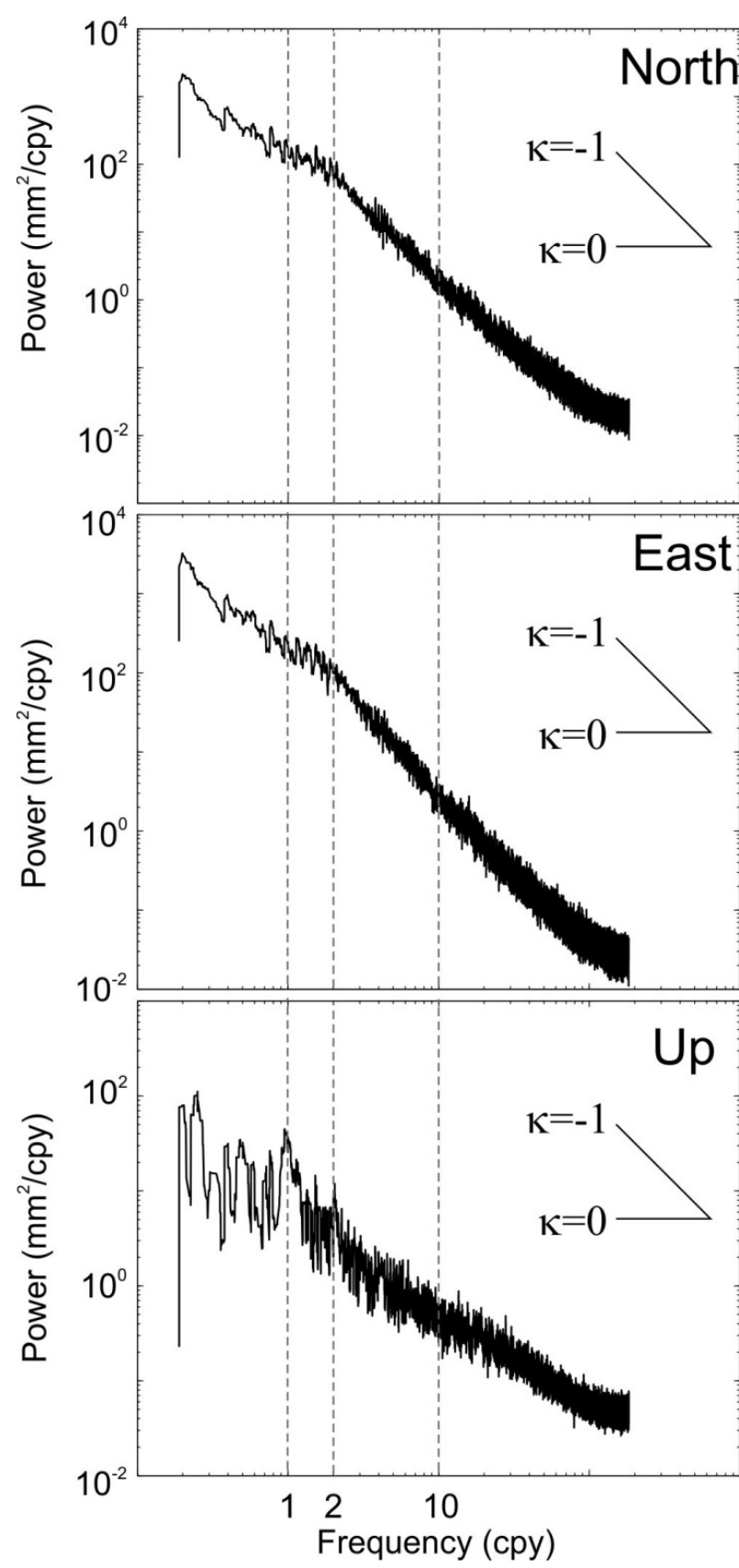

Fig. 1 Stacked PSDs averaged with moving window for a set of 115 European stations for North, East and Up components. The PSDs reveal clear oscillations between 1 and 10 cpy in vertical direction. However, they are almost flat for horizontal components. They only reveal slight growth in power between 1 and 4 cpy.

\section{SEASONAL SIGNALS}

In the following research, we estimated the seasonal signals in the form of sine curves using MLE resolving for all parameters of data at the same time.. In this section we only discuss the amplitudes and phases of annual and semi-annual tropical and draconitic periods, as these contribute the most to GPS data. As was shown by Gruszczynska et al. (2016), the tropical annual signal (365.25 days) may constitute as much as $30 \%$ of total variance of entire data for European height time series, whereas, the variance of height time series comprises in less than $10 \%$ of the tropical semi-annual signal (182.63 days). The phases of annual signal estimated for vertical component for a set of 115 European stations are in a good agreement for Central European stations (Fig. 2). Maxima of annual sinusoid fall between June and July. The amplitudes of tropical annual sinusoid are much smaller for coastal stations between 1 and 3 $\mathrm{mm}$, while start to increase when we move further towards Eastern Europe. The highest amplitudes were noticed in this research for stations situated in Ukraine, Romania, Bulgaria and Turkey with a maximum of $8.4 \mathrm{~mm}$ estimated for KHAR (Kharkiv, Ukraine). The Icelandic, Greenland and Svalbard stations differ in phase comparing to European continental stations. However, they stay consistent with each other with maxima falling in December. The amplitudes and phases of tropical annual sinusoid estimated in this research for vertical component for Icelandic, Svalbard and Central European stations are in a good agreement with the results of annual signal estimated by Collilieux et al. (2007) for a set of global IGS ITRF2005 series. However, few stations differ from what was shown for ITRF2005. These are: e.g. MADR (Madrid, Spain), METS (Metsahovi, Finland), TROM (Tromso, Norway) or KIRU (Kiruna, Sweden). Although the amplitude of annual signal remains at almost the same level, phases differ between ITRF2005 and ITRF2014 of 1-3 months. Amplitudes and phases for horizontal components are spatially uncorrelated and do not show any significant pattern. The median amplitudes of tropical annual signal are equal to $0.8 \mathrm{~mm}$ and $0.6 \mathrm{~mm}$ for North and East, respectively (Table 1) with a median formal error estimated assuming a combination of power-law and white noises equal to $0.15 \mathrm{~mm}$. The median amplitudes of tropical semi-annual signal are equal to $0.2 \mathrm{~mm}$ for North and East components and to $0.5 \mathrm{~mm}$ for Up component. In this research, the maximum amplitude of semi-annual signal $(2.7 \mathrm{~mm})$ in vertical direction was noticed for station VAAS (Vaasa, Finland). Those residual oscillations may come from atmospheric (van Dam and Wahr, 1987), non-tidal ocean (van Dam et al., 2012) or continental water (van Dam et al., 2001) loadings, they may also have the origin in mismodeling in short periods (Penna and Stewart, 2003). However, this investigation is out of the scope of this research.

Collilieux et al. (2007) and Ray et al. (2008) used the global IGS ITRF2005 time series and showed that the draconitic year can be detected up to its sixth overtone. By proving the existence of draconitics, they emphasized the need of their modelling during GPS time series analysis. Having fixed the ambiguities, King and Watson (2010) reduced the amplitudes of draconitics, however, they were not able to entirely reduce them. Therefore we need to model the draconitics on the station-by-station basis during the analysis of time series. In this analysis, the 


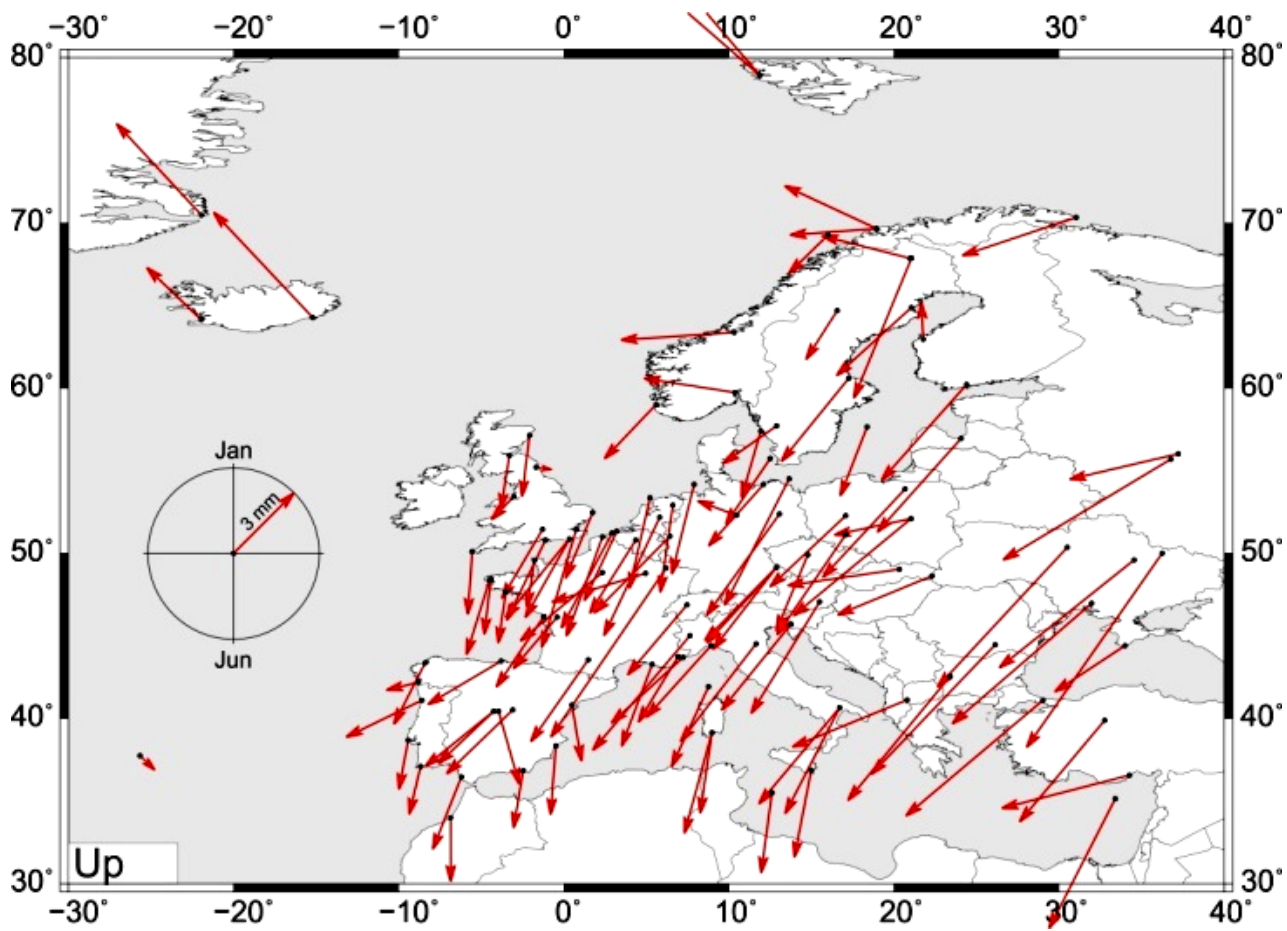

Fig. 2 Amplitude of tropical annual signal $(\mathrm{mm})$ in vertical direction estimated for a set of 115 European IGS stations that contributed into ITRF2014. The length of arrow means the amplitude of annual sine, while the phase is counted clockwise from north meaning January.

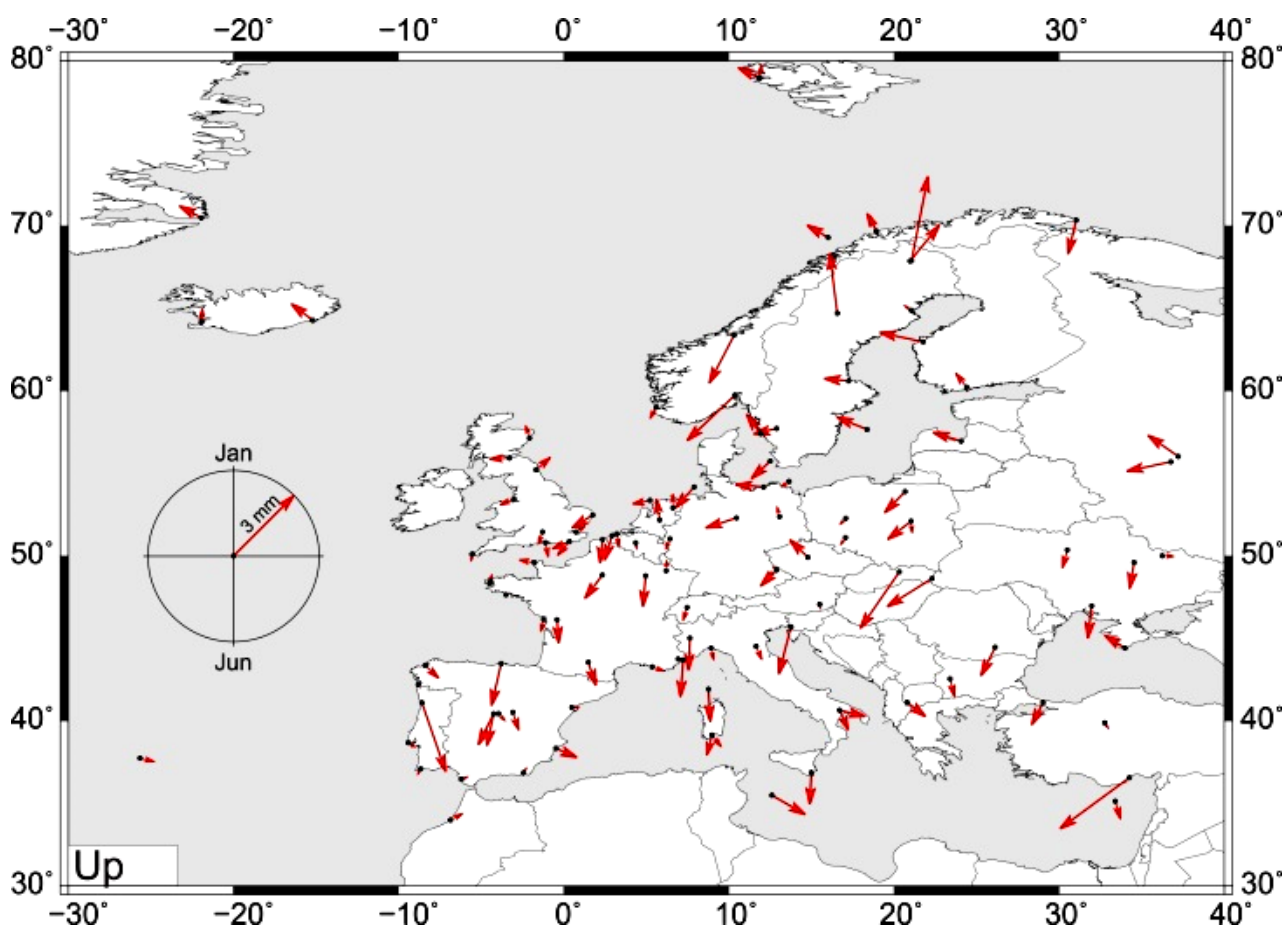

Fig. 3 Amplitude of draconitic annual signal $(\mathrm{mm})$ in vertical direction estimated for a set of 115 European IGS stations that contributed into the latest release of ITRF. Same scale was sustained for better comparison to Figure 2. 
Table 1 Statistics of first and second tropical (365.25 days) and draconitic (351.60 days) harmonics estimated for a set of European stations in horizontal and vertical directions. Statistic is given as minimum, maximum and median amplitudes. The median formal error of amplitudes estimated assuming a combination of power-law and white noises is equal to $0.15 \mathrm{~mm}$ for North and East and $0.25 \mathrm{~mm}$ for Up component.

\begin{tabular}{lcccccccccccc}
\hline & \multicolumn{4}{c}{ North [mm] } & \multicolumn{1}{c}{ East [mm] } & \multicolumn{4}{c}{ Up [mm] } \\
\cline { 2 - 40 } & 365.25 & 182.63 & 351.60 & 175.80 & 365.25 & 182.63 & 351.60 & 175.80 & 365.25 & 182.63 & 351.60 & 175.80 \\
\hline MIN & 0.2 & 0.0 & 0.1 & 0.1 & 0.1 & 0.0 & 0.0 & 0.1 & 0.6 & 0.1 & 0.2 & 0.2 \\
MAX & 5.3 & 0.9 & 1.2 & 0.7 & 2.7 & 0.7 & 0.9 & 0.7 & 8.4 & 2.7 & 3.1 & 1.7 \\
MED & 0.8 & 0.2 & 0.4 & 0.3 & 0.6 & 0.2 & 0.3 & 0.4 & 3.2 & 0.5 & 0.8 \\
\hline
\end{tabular}

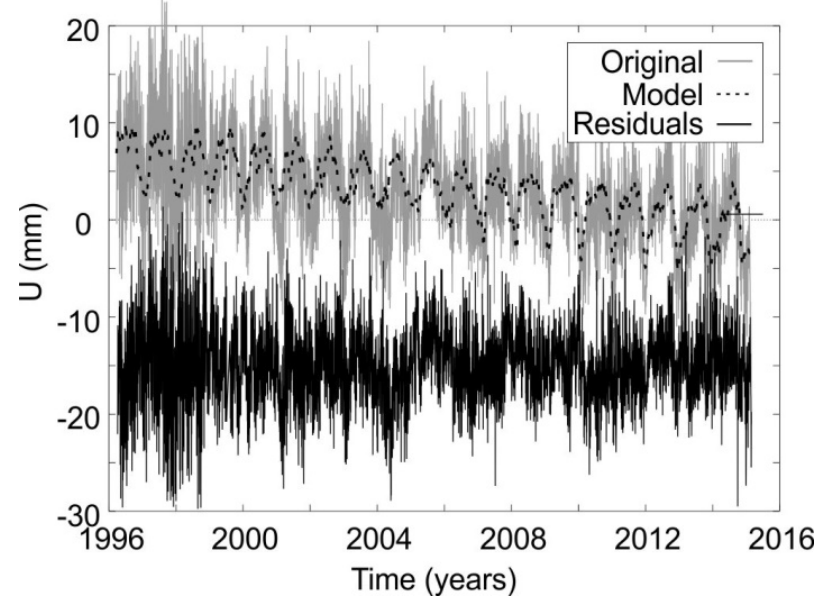

Fig. 4 Time series for SFER (San Fernando, Spain) in Up direction (grey). Deterministic model we applied is plotted with a black dashed line. Up component was purposely shifted for better visibility.

draconitic frequency is only observed for its first and second harmonics (see the Methodology sub-section and a description of Power Spectral Density). Draconitic annual signal reach the maximum amplitudes of 1.2 and $0.9 \mathrm{~mm}$ for North and East, respectively, whereas is slightly higher for $\mathrm{Up}$ component with a maximum of $3.1 \mathrm{~mm}$ (Fig. 3). The median of semi-annual signal reaches $0.8 \mathrm{~mm}$ in vertical direction with a maximum of $1.7 \mathrm{~mm}$. As expected from the nature of draconitics (AmiriSimkooei, 2013) no spatial dependencies were found.

\section{STOCHASTIC PART}

In the following study, we employed MLE and analysed residuals of 115 GPS stations to get the estimates of a character of the stochastic part. Having provided the individual amplitudes and spectral indices of power-law behaviour, we were able to obtain errors of parameters influenced by power-law noise. All of the 115 stations show clear power-law behaviour for individual residuals. Figure 5 presents exemplary PSD estimated for SFER (San Fernando, Spain) station with a fitted model being a combination of power-law and white noises. Values of spectral indices estimated for North, East and Up components are also given on the plot and are equal to $-1.19,-1.23$ and -0.94 , respectively. All individual residuals reveal obvious power-law behaviour close to flicker noise between low frequencies up to approximately 100 cpy. Moving towards the end of the spectrum, the PSD becomes flat, revealing a pure white noise in the highest frequencies. Such a power-law behaviour was also previously noticed by number of authors as Teferle et al. (2008), Williams et al. (2004) or Klos et al. (2016b).

In this study, the spectral indices and amplitudes of power-law noise were estimated with MLE. The spectral indices fall between -1.18 and -0.48 (median -0.84) for North, between -1.31 and -0.35 (median -0.79) for East and between -1.37 and -0.37 (median -0.81) for Up component (Fig. 6). The indices are spatially uncorrelated for horizontal components, whereas some pattern can be noticed for Up component. Stations in Central and Northern Europe are characterized by spectral index between flicker and random-walk noise, while stations in Southern and Western Europe reveal a character between white and flicker noise. This may be caused by large scale phenomena, e.g. hydrology or atmosphere, which influences a large area of Central Europe. It may also arise from the influence of Baltic sea. Bos et al. (2013b) found a good correlation for tide gauge records mounted at the coastal area of Baltic sea. The stochastic properties of these tide gauge records differed a lot from any other region of the world. Klos et al. (2017) found obvious correlations between changes of the station position and atmospheric and hydrological (continental and ocean non-tidal) loadings, provided improvement of the Root Mean Squares (RMS) up to $45 \%$.

Although a shift in spectral index from flicker towards random-walk noise is associated with local phenomena as multipath or inadequate monument for GPS antennae, this large scale phenomenon we noticed in this research is too spatially correlated to arise from local effects or inadequate monument. The smallest spectral index equal to -1.37 was noticed for MAR6 (Maartsbo, Sweden) station Up component. Nevertheless, referring to the reliable velocities, the smaller the spectral index, the greater the influence it will have on the uncertainty of velocity. This is why we expect, that velocity uncertainties will significantly differ from the official ITRF2014 uncertainties estimated with white noise for stations where spectral index fall far from uncorrelated white noise. 

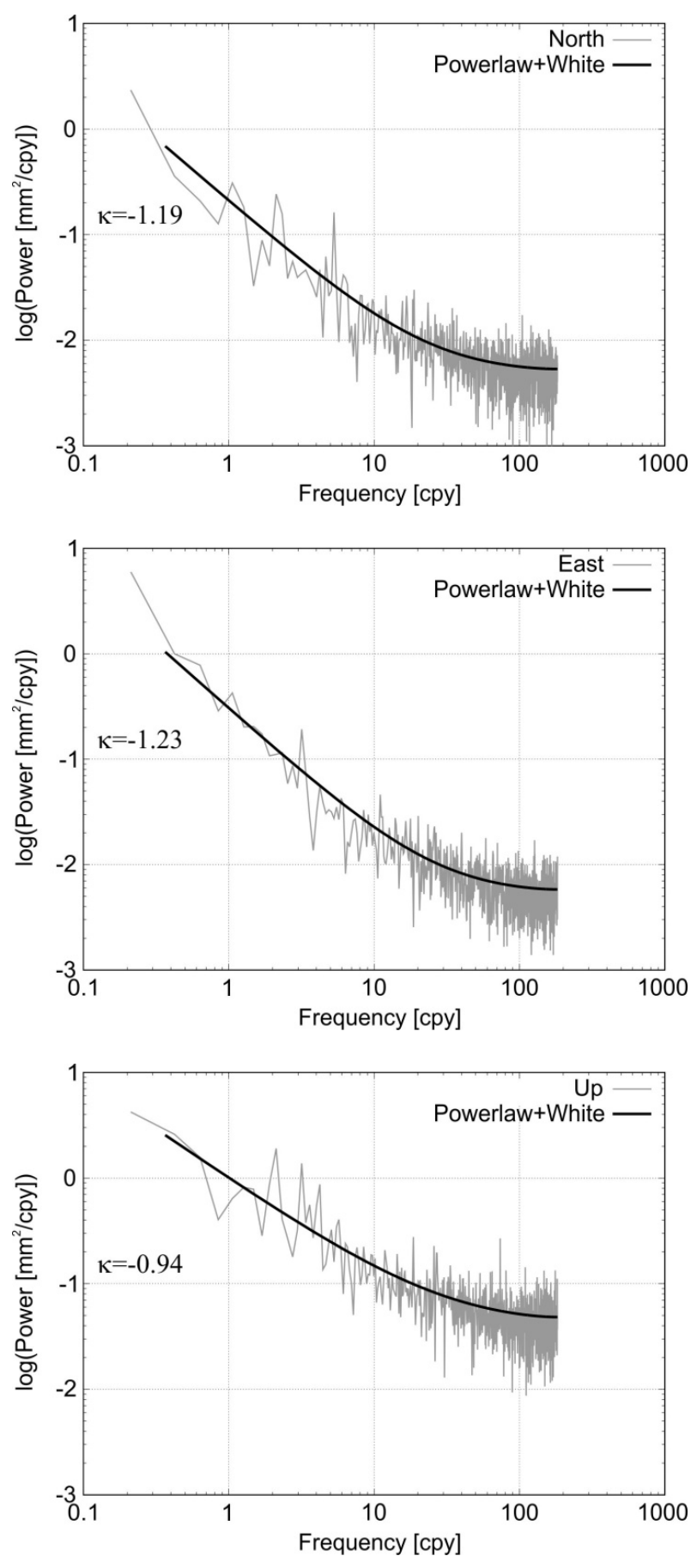

Fig. 5 Individual PSD for SFER (San Fernando, Spain) station presented for North, East and Up components in grey. Combination of power-law and white noises model was fitted with a black line. Spectral index of power-law noise estimated with MLE is given at each plot.

Figure 7 shows the amplitudes of power-law noise estimated for a set of 115 stations situated in Europe. The amplitudes fall between 1.97 and $5.87 \mathrm{~mm} / \mathrm{yr}^{-\mathrm{K} / 4}$ (median 3.04) for North, between 1.96 and 4.77 (median 2.96) for East and between 5.79 and 31.31 (median 12.60) for Up components. No spatial dependencies were found for horizontal components. However, a clear pattern was noticed for Up component. Again, all stations situated at the coast of Baltic Sea are much noisier than the ones situated in Western and Southern Europe. The highest amplitude of 31.31 was found for VAAS (Vaasa, Finland) station. According to Eq. (3), the amplitude of powerlaw noise will influence the estimates of velocity uncertainty among with the spectral index.

\section{VELOCITIES AND THEIR FORMAL UNCERTAINTIES}

In the following research, the reliable velocities and their uncertainties were aimed at and the lately released official velocity errors for ITRF2014 stations are discussed. While the ITRF2014 uncertainties were estimated with a pure white noise, in this study we assumed that the stochastic part follows the combination of power-law and white noise. These uncertainties are being compared with the official uncertainties of ITRF2014 velocities estimated with white noise only character. The comparison is delivered in a form of Dilution of Precision $(D P)$, which is a ratio between uncertainties estimated with a combination of power-law and white noises and white-noise-only:

$$
D P=\frac{\sigma_{W N-P L}}{\sigma_{W N}}
$$

Altamimi et al. (2011) and Altamimi et al. (2016) stated that the formal errors of horizontal and vertical ITRF2008 and ITRF2014 velocities are less than $0.2 \mathrm{~mm} / \mathrm{yr}$. However, they were all estimated with white noise assumption. Figure 8 presents a comparison when a pure white noise is assumed instead of power-law character. Values of $D P$ are between 2.1 and 17.4 for North, $1.4 \div 31.6$ for East and $1.7 \div 52.5$ for Up components. The highest $D P$ s were found for North, East and Up for: ISTA (Istanbul, Turkey), SHEE (Sheerness, UK), VAAS (Vaasa, Finland) station. A number of $13 \%$ of stations has a $D P$ larger than 10 for North and East, whereas a number of $30 \%$ has a $D P$ larger than 10 for Up component. A median $D P$ is equal to 6 for horizontal and to 7 for vertical direction. The above presented numbers mean that we can be misled by 7 times on average when white noise is being employed instead of power-law behaviour. This may in consequence lead to improper interpretations of velocities.

\section{DISCUSSION \& CONCLUSIONS}

The presented study described the uncertainty estimation of velocities derived from GPS position time series. These uncertainties were estimated based on appropriate deterministic model of GPS data and a realistic noise model. We analysed the Power Spectral Densities of a set of 115 European IGS stations. We determined all significant oscillations and employed them in the MLE analysis of GPS position time series. We found that phases of annual signal estimated for analysed stations are in a good agreement for Central European stations and maxima 
of annual sinusoid fall between June and July. The amplitudes of tropical annual sinusoid are much smaller for coastal stations between 1 and $3 \mathrm{~mm}$, while start to increase when we move further towards Eastern Europe. These results are in a good agreement with Collilieux et al. (2007) who presented seasonal signals for a set of global IGS stations.

Up to now, the noise in GPS position time series were estimated in numerous studies by e.g. Zhang et al. (1997), Mao et al. (1999) or Williams et al. (2004). Recently, Klos et al. (2016) showed that European IGS stations (Military University of Technology EPN Analysis Centre network solution) follow a character of power-law noise between white and flicker noise with amplitudes falling in 3-5 mm/ $\mathrm{yr}^{-\mathrm{k} / 4}$ for horizontal components and in $5-12 \mathrm{~mm} / \mathrm{yr}^{-\mathrm{k} / 4}$ for vertical component. In this research, we estimated the character and amplitudes of power-law noise for a set of European stations that contributed to the latest realization of ITRS. The spectral indices estimated for the chosen set of stations fall between -1.18 and -0.48 (median -0.84) for North, between -1.31 and -0.35 (median -0.79 ) for East and between -1.37 and -0.37 (median -0.81) for Up component, while the amplitudes fall between 1.97 and 5.87 (median 3.04) for North, between 1.96 and 4.77 (median 2.96) for East and between 5.79 and 31.31 (median 12.60) for Up component. A clear spatial dependence can be noticed for vertical component, for which stations situated at the coast of Baltic Sea are much noisier than the ones located in South and West Europe. These stations are characterized by spectral indices between flicker and random-walk noise and few times greater amplitudes.

This study focuses on the estimates of Dilution of Precision, i.e. how much one may be misled with values of velocity uncertainty when a wrong noise model is being assumed. Having applied appropriate mathematical model to GPS position time series, we estimated the values of errors of parameters we employed. These are mainly influenced by a covariance matrix of power-law noise $\mathbf{C}_{\mathbf{x}}$ :

$$
\mathbf{C}_{\mathbf{y}}=\left[\mathbf{A}^{\mathrm{T}} \mathbf{C}_{\mathbf{x}}^{-1} \mathbf{A}\right]^{-1}
$$

where $\mathbf{A}$ is a design matrix for a mathematical model employed in Eq. (1). Previously, Zhang et al. (1997) stated that the uncertainties of velocities are approximately 3-6 times larger when a combination of white plus flicker noise is employed instead of white noise. Williams et al. (2004) or Kenyeres and Bruyninx (2009) stated that the uncertainty of velocity may be underestimated by a factor of 2-11 when pure white noise is used instead of power-law noise. Klos et al. (2015) found that uncertainties may be underestimated up to $5 \mathrm{~mm} / \mathrm{yr}$ when white noise is employed. In this research, we estimated the $D P \mathrm{~s}$ as a ratio between uncertainty estimated with a combination of power-law and white noises to the uncertainty estimated with white noise only (see Eq. (4)). The latter one was adopted from the official uncertainties released in the ITRF2014. We showed that a number of $13 \%$ and $30 \%$ of stations has a $D P$ larger than 10 for horizontal and vertical components, respectively. Finally, we determined the median $D P$ which is equal to 6 for horizontal and to 7 for vertical direction.

\section{ACKNOWLEDGMENTS}

Maps and charts were drawn in GMT (Generic Mapping Tool, Wessel et al., 2013).

This research was supported by the Military University of Technology Faculty of Civil Engineering and Geodesy statutory research funds.

\section{REFERENCES}

Altamimi, Z., Collilieux, X. and Métivier, L.: 2011, ITRF2008: an improved solution of the international terrestrial reference frame. J. Geod., 85, 457. DOI: $10.1007 / \mathrm{s} 00190-011-0444-4$

Altamimi, Z., Rebischung, P., Métivier, L. and Collilieux, X.: 2016, ITRF2014: A new release of the International Terrestrial Reference Frame modelling nonlinear station motions. J. Geophys. Res. Solid Earth, 121, 6109-6131. DOI: 10.1002/2016JB013098

Amiri-Simkooei, A.R.: 2013, On the nature of GPS draconitic year periodic pattern in multivariate position time series. J. Geophys. Res. Solid Earth, 118, 2500-2511. DOI:10.1002/jgrb.50199

Beavan, J.: 2005, Noise properties of continuous GPS data from concrete pillar geodetic monuments in New Zealand and comparison with data from U.S. deep drilled braced monuments. J. Geophys. Res., 110, B08410. DOI: 10.1029/2005JB003642

Beutler, G., Rothacher, M., Schaer, S., Springer, T.A., Kouba, J. and Neilan, R.E.: 1999, The International GPS Service (IGS): an interdisciplinary service in support of Earth sciences. Adv. Space Res., 23, 631635. DOI: 10.1016/S0273-1177(99)00160-X

Bevis, M. and Brown, A.: 2014, Trajectory models and reference frames for crustal motion geodesy. J. Geod., 88, 283-311. DOI: 10.1007/s00190-013-0685-5

Blewitt, G. and Lavallée, D.: 2002, Effect of annual signals on geodetic velocity. J. Geophys. Res., 107, 2145. DOI: 10.1029/2001JB000570

Bogusz, J. and Klos, A.: 2016, On the significance of periodic signals in noise analysis of GPS station coordinates time series. GPS Solut., 20, 655-664. DOI 10.1007/s10291-015-0478-9

Bos, M.S., Fernandes, R.M.S., Williams, S.D.P. and Bastos, L.: 2008, Fast error analysis of continuous GPS observations. J. Geod., 82, 157-166. DOI: $10.1007 / \mathrm{s} 00190-007-0165-\mathrm{x}$

Bos, M., Bastos, L. and Fernandes, R.M.S.: 2010, The influence of seasonal signals on the estimation of the tectonic motion in short continuous GPS time-series. J. Geodyn., 49, 205-209. DOI: 10.1016/j.jog.2009.10.005

Bos, M., Fernandes, R.M.S., Williams, S.D.P. and Bastos, L.: 2013a, Fast error analysis of continuous GNSS observations with missing data. J. Geod., 87, 351-360. DOI: 10.1007/s00190-012-0605-0

Bos, M.S., Williams, S.D.P., Araújo, I. B. and Bastos, L.: 2013b, The effect of temporal correlated noise on the sea level rate and acceleration uncertainty. Geophys. J. Int., 196, 3, 1423-1430. DOI: 10.1093/gji/ggt481

Campbell, J. and Nothnagel, A.: 2010, Intra-plate deformation in west-central Europe. J. Geodyn., 49, 130-140. DOI:10.1016/j.jog.2009.10.004 
Collilieux, X., Altamimi, Z., Coulot, D., Ray, J. and Sillard, P.: 2007, Comparison of very long baseline interferometry, GPS, and satellite laser ranging height residuals from ITRF2005 using spectral and correlation methods. J. Geophys. Res., 112, B12403. DOI: $10.1029 / 2007$ JB004933

Gruszczynska, M., Klos, A., Gruszczynski, M. and Bogusz, J.: 2016, Investigation of time-changeable seasonal components in the GPS height time series: A case study for Central Europe. Acta Geodyn. Geomater., 13, No. 3 (183), 281-289. DOI: $10.13168 /$ AGG.2016.0010

Kenyeres, A. and Bruyninx, C.: 2009, Noise and periodic terms in the EPN time series. Geodetic Reference Frames. International Association of Geodesy Symposia 134, H. Drewes (ed.), Springer-Verlag Berlin Heidelberg.

DOI: $10.1007 / 978-3-642-00860-322$

Kierulf, H.P., Steffen, H., Simpson, M.J.R., Lidberg, M., Wu, P. and Wang, H.: 2014, A GPS velocity field for Fennoscandia and a consistent comparison to glacial isostatic adjustment models. J. Geophys. Res. Solid Earth, 119, 6613-6629. DOI: 10.1002/2013JB010889

King, M. and Watson, C.: 2010, Long GPS coordinate time series: multipath and geometry effects. J. Geophys. Res., 115, B04403. DOI: 10.1029/2009JB006543

Klos, A., Bogusz, J., Figurski, M. and Kosek, W.: 2014, Uncertainties of geodetic velocities from permanent GPS observations: the Sudeten case study. Acta Geodyn. Geomater., 11, 3, 201-209. DOI: 10.13168/AGG.2014.0005

Klos, A., Bogusz, J., Figurski, M. and Kosek, W.: 2015, Irregular variations in GPS time series by probability and noise analysis. Survey Review, 47, 342, 163-173. DOI: $10.1179 / 1752270614$ Y.0000000133

Klos, A., Bogusz, J., Figurski, M. and Kosek, W.: 2016, Noise analysis of continuous GPS time series of selected EPN stations to investigate variations in stability of monument types. Springer IAG Symposium Series, 142, 19-26. DOI: $10.1007 / 1345$ 2015 62

Klos, A., Bogusz, J., Figurski, M. and Gruszczynski, M.: 2016, Error analysis for European IGS stations. Studia Geophysica et Geodaetica, 60, 1, 17-34. DOI: $10.1007 / \mathrm{s} 11200-015-0828-7$

Klos, A., Gruszczynska, M., Bos, M.S., Boy, J.-P. and Bogusz, J.: 2017. Estimates of vertical velocity errors for IGS ITRF2014 stations by applying the Improved Singular Spectrum Analysis method and environmental loading models. Pure and Applied Geophysics. DOI: 10.1007/s00024-017-1494-1

Lomb, N.R.: 1976, Least-squares frequency analysis of unequally spaced data. Astrophysics and Space Science, 39, 2, 447-462. DOI: 10.1007/BF00648343

Mao, A., Harrison, C.G.A. and Dixon, T.H.: 1999, Noise in GPS coordinate time series. J. Geophys. Res., 104, B2, 2797-2816. DOI: 10.1029/1998JB900033

McCarthy, D. D., and Petit, G.: 2004, IERS conventions: 2003. IERS Tech. Note 32, Int. Earth Rotation and Ref. Syst. Serv., Frankfurt am Main, Germany.

Métivier, L., Collilieux, X. and Altamimi, Z.: 2012, ITRF2008 contribution to glacial isostatic adjustment and recent ice melting assessment. Geophys. Res. Lett., 39, L01309. DOI: 10.1029/2011GL049942
Penna, N.T. and Stewart, M.P.: 2003, Aliased tidal signatures in continuous GPS height time series. Geophys. Res. Lett., 30, 23, 2184. DOI: 10.1029/2003GL018828

Ray, J., Altamimi, Z., Collilieux, X. and van Dam, T.: 2008, Anomalous harmonics in the spectra of GPS position estimates. GPS Solut., 12, 1, 55-64. DOI: 10.1007/s10291-007-0067-7

Rebischung, P., Altamimi, Z., Ray, J. and Garayt, B.: 2016, The IGS contribution to ITRF2014. J. Geod., 90, 611630. DOI: $10.1007 / \mathrm{s} 00190-016-0897-6$

Scargle, J.D.: 1982, Studies in astronomical time series analysis. II - Statistical aspects of spectral analysis of unevenly spaced data. Astrophysical Journal, 263, 2, 835-853. DOI: 10.1086/160554

Teferle, F.N., Bingley, R.M., Williams, S.D.P., Baker, T.F. and Dodson, A.H.: 2006, Using continuous GPS and absolute gravity to separate vertical land movements and changes in sea-level at tide-gauges in the UK. Phil. Trans. R. Soc. A, 364, 917-930. DOI: $10.1098 /$ rsta.2006.1746

Teferle, F.N., Williams, S.D.P., Kierulf, H., Bingley, R. and Plag, H.-P.: 2008, A continuous GPS coordinate time series analysis strategy for high-accuracy vertical land movements. Physics and Chemistry of the Earth, 33, 205-216. DOI: 10.1016/j.pce.2006.11.002

Wessel, P., Smith, W.H.F., Scharroo, R., Luis, J. and Wobbe, F.: 2013, Generic Mapping Tools: Improved Version Released. Eos, Transactions, American Geophysical Union, 94, 45, 409-410. DOI: $10.1002 / 2013 E O 450001$

van Dam, T. and Wahr, J.M.: 1987, Displacements of the Earth's surface due to atmospheric loading: effects on gravity and baseline measurements. J. Geophys. Res., Solid Earth, 92, B2, 1281-1286.

DOI:10.1029/JB092iB02p01281

van Dam, T., Wahr, J., Milly, P.C.D., Shmakin, A.B., Blewitt, G., Lavallee, D. and Larson, K.M.: 2001, Crustal displacement due to continental water loading. Geophys. Res. Lett., 28, 651-654. DOI: $10.1029 / 2000$ GL012120

van Dam, T., Collilieux, X., Wuite, J., Altamimi, Z. and Ray, J.: 2012, Nontidal ocean loading: amplitudes and potential effects in GPS height time series. J. Geod., 86, 1043-1057. DOI: 10.1007/s00190-012-0564-5

Williams, S.D.P., Bock, Y., Fang, P., Jamason, P., Nikolaidis, R.M., Prawirodirdjo, L., Miller, M. and Johnson, D.: 2004, Error analysis of continuous GPS position time series. J. Geophys. Res., 109, B03412. DOI: 10.1029/2003JB002741

Wöppelmann, G. and Marcos, M.: 2016, Vertical land motion as a key to understanding sea level change and variability. Rev. Geophys., 54, 1, 64-92. DOI: $10.1002 / 2015 R G 000502$

Zhang, J., Bock, Y., Johnson, H., Fang, P., Williams, S.D.P., Genrich, J., Wdowinski, S. and Behr, J.: 1997, Southern California Permanent GPS Geodetic Array: Error analysis of daily position estimates and site velocities. J. Geophys. Res., 102, B8, 18,035-18,055. DOI: 10.1029/97JB01380 


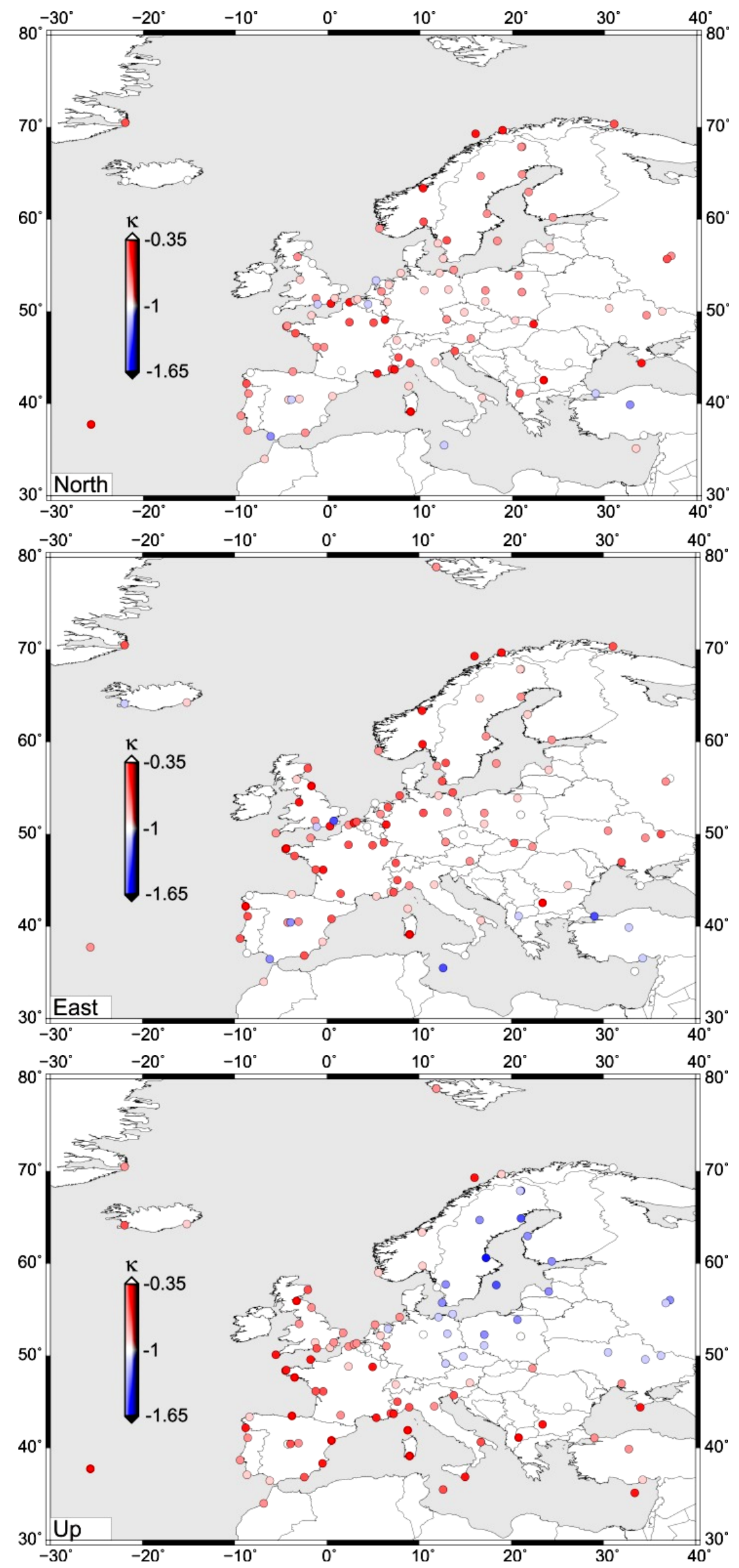

Fig. 6 Spectral indices of power-law noise estimated with MLE for a set of 115 European stations that contributed into ITRF2014. North, East and Up components are plotted from the top. Flicker noise is plotted in white, while all indices smaller than -1 (towards white noise) are red. All indices higher than flicker noise (towards random-walk) are plotted with blue. 


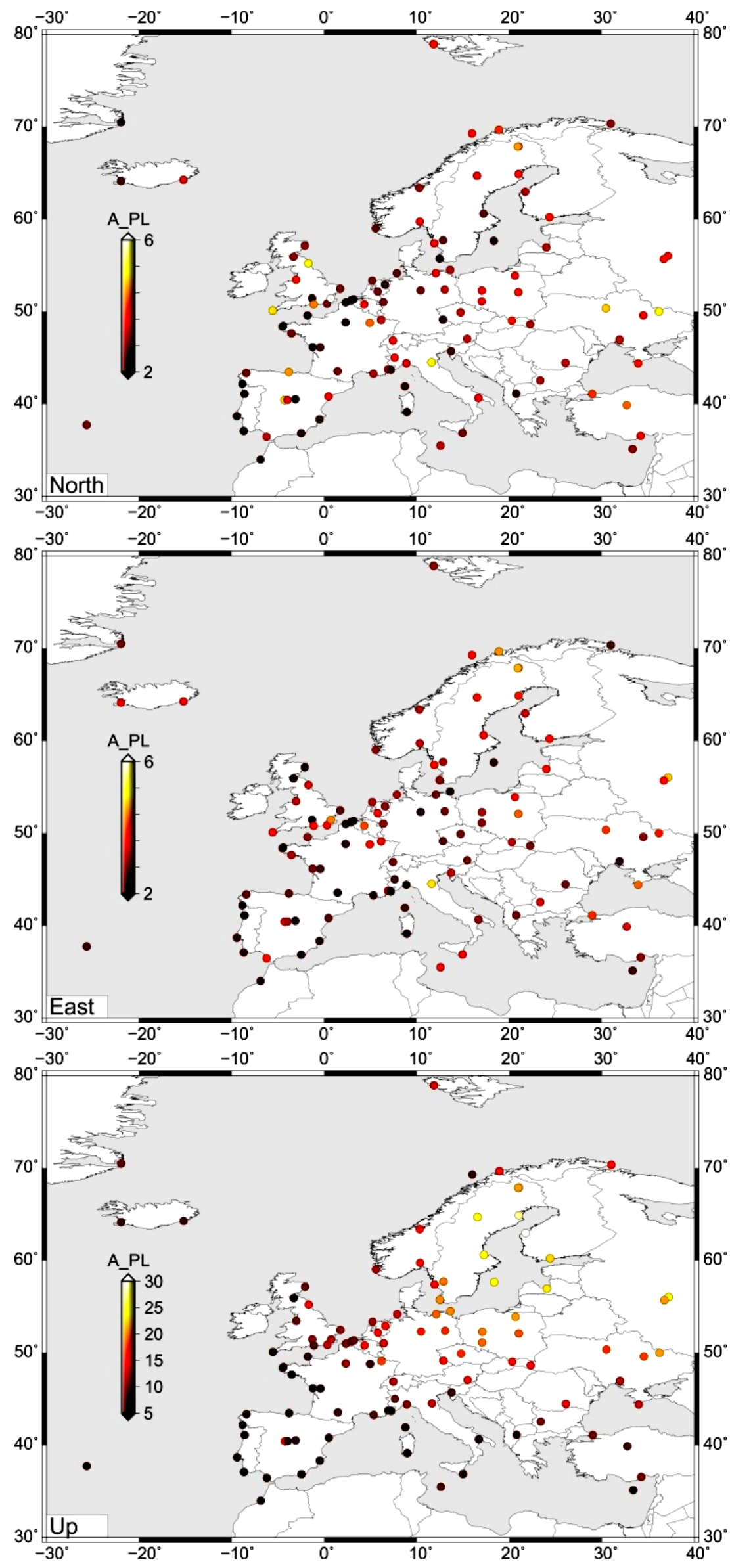

Fig. 7 The amplitudes of power-law noise $\left(\mathrm{mm} / \mathrm{yr}^{-\kappa / 4}\right)$ estimated with MLE for a set of European stations. The North, East and Up components are plotted starting from the top. Different scales in horizontal and vertical directions were applied. 


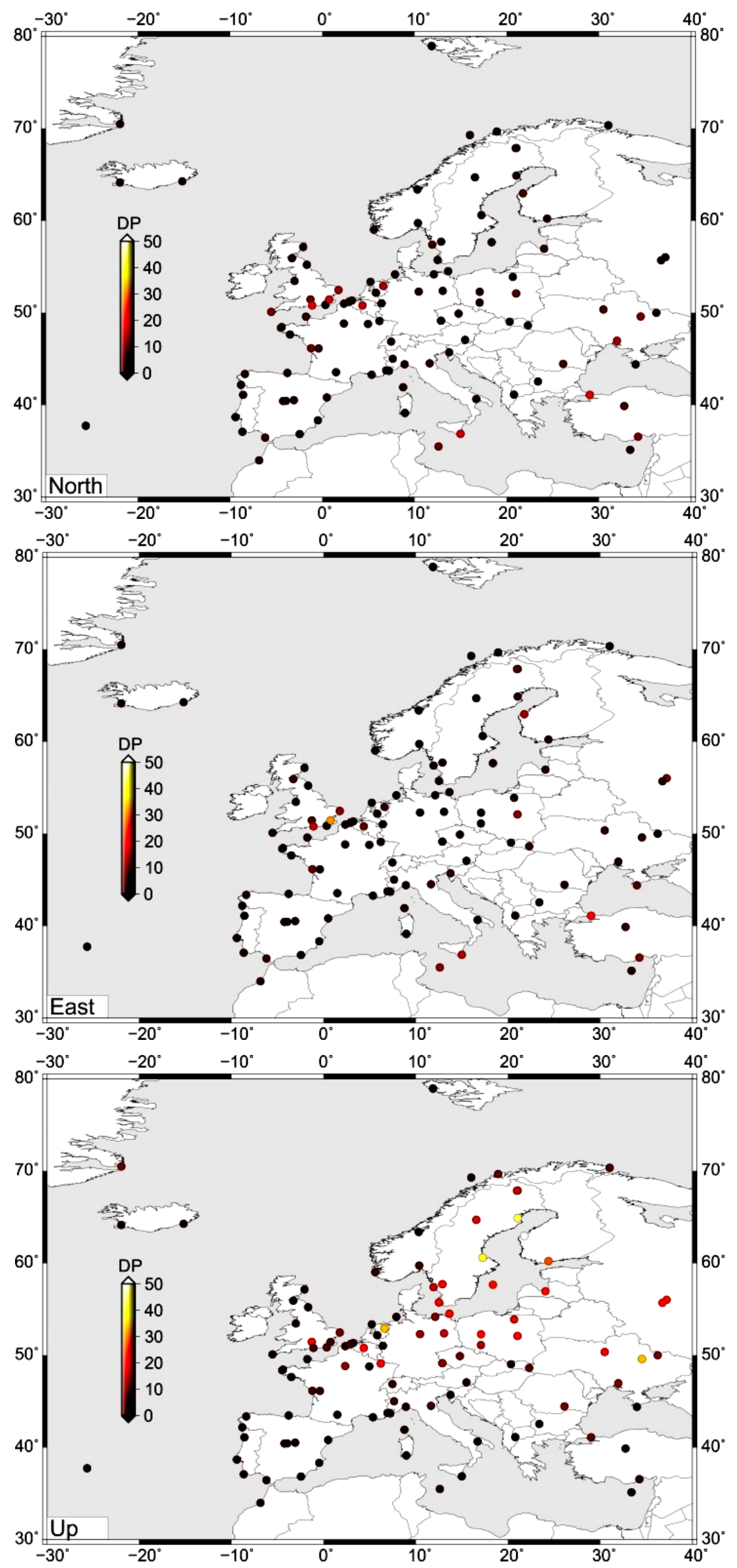

Fig. 8 Dilution of Precision for a set of 115 European stations that contributed into ITRF2014. 